\title{
Unilateral Angle-Closure Glaucoma with Ciliochoroidal Effusion after the Consumption of Cannabis: A Case Report
}

\author{
Rana Hanna $^{\mathrm{a}}$ Beatrice Tiosano $^{\mathrm{a}} \quad$ Noora Dbayat $^{\mathrm{a}}$ Dan Gaton ${ }^{\mathrm{b}}$ \\ ${ }^{a}$ Department of Ophthalmology, Hillel-Yaffe Medical Center, Hadera, and ${ }^{b}$ Department of \\ Ophthalmology, Rabin Medical Center and Sackler Faculty of Medicine, Tel Aviv \\ University, Tel Aviv, Israel
}

\section{Key Words}

Angle-closure glaucoma · Ciliochoroidal effusion · Cannabis · Marijuana · Myopic shift

\begin{abstract}
A 35-year-old male patient, diagnosed with acute angle-closure glaucoma, did not improve despite intensive treatment with antiglaucoma medications. Ultrasound biomicroscopy revealed a ciliochoroidal effusion. Due to his past history of drug abuse, a urine test was analyzed and found to be positive for cannabis. After topical cycloplegia and oral steroid therapy, his symptoms improved substantially. The present case highlights the role of ultrasound biomicroscopy in evaluating patients with acute angle-closure glaucoma and the role of cannabis abuse in the development of ciliochoroidal effusion.

(c) 2014 S. Karger AG, Basel
\end{abstract}

\section{Case Presentation}

A 35-year-old male patient was admitted to our emergency room due to severe right eye pain for 2 days prior to his arrival. There was no significant ocular or medical history. He was not on any prescribed systemic or ocular medication. He reported good visual acuity and no refractive correction.

On initial examination, his best-corrected visual acuity was 20/80 OD and 20/20 OS. Intraocular pressure (IOP) was $25 \mathrm{~mm} \mathrm{Hg}$ OD and $12 \mathrm{~mm} \mathrm{Hg}$ OS. A slit-lamp examination of the right eye revealed a hyperemic conjunctiva, a shallow central and peripheral anterior chamber depth, and his pupil was miotic. His left eye examination was unremarkable. A 
Hanna et al.: Unilateral Angle-Closure Glaucoma with Ciliochoroidal Effusion after the Consumption of Cannabis: A Case Report

gonioscopy on his OD revealed a closed angle, not reacting to indentation. The OS anterior chamber angle was wide open. He developed an acute myopic shift of -2.5 diopters OD and 0.5 OS. The axial length was $23.67 \mathrm{~mm}$ OD and $23.84 \mathrm{~mm}$ OS. Fundus examination, including the optic nerve head, was normal in both eyes. He was treated with topical applications of pilocarpine $2 \%$ every $15 \mathrm{~min}$ for $2 \mathrm{~h}$, timolol $0.5 \%$ every $12 \mathrm{~h}$, brimonidine $0.2 \%$ every $12 \mathrm{~h}$, and acetazolamide $1 \%$ every $12 \mathrm{~h}$. After $1 \mathrm{~h}$, his IOP returned to normal and the symptoms decreased. After $2 \mathrm{~h}$ following this improvement, he reported a recurrence of the symptoms, and an elevation of his IOP (26 mm Hg OD) was noticed.

An ultrasound biomicroscopy (UBM) was performed to evaluate the angle and ciliary body region (fig. 1, fig. 2). An UBM of his OD revealed a closed angle, choroidal effusion, anteriorly rotated ciliary processes, and obscure ciliary sulci (fig. 1, fig. 2). The performed UBM of his OS revealed an open angle and no signs of choroidal effusion. Treatment with topical cycloplegia and oral steroids was started, and his symptoms improved substantially.

His visual fields were normal in both eyes, and the retinal fluorescein angiography was normal. Repeated enquiries about medication or drug use revealed marijuana abuse. A urine test for toxic substances was found to be positive for cannabis.

\section{Discussion}

Angle closure is often erroneously considered synonymous with a pupillary block, the most common mechanism leading to acute or chronic iridocorneal apposition. Ritch et al. [1] and Tello et al. [2] have described a 4-point classification of these mechanisms and, in addition to a pupillary block occurring at the level of the iris, have included mechanisms originating in the ciliary body, lens, or posterior segment.

UBM has led to the description of clinical cases indistinguishable from malignant glaucoma. These cases, in which the accumulation of supraciliary fluid leads to the detachment and anterior rotation of the ciliary body and consequent angle closure, may be part of diffuse choroidal detachments observable with B-scan ultrasounds, or a subtle finding observable only with UBM. Medical therapy only may be indicated for these patients, highlighting the need for a careful diagnosis.

Several classes of drugs are known to precipitate angle-closure glaucoma including adrenergic agonists, cholinergics, anticholinergics, sulpha-based drugs, selective serotonin reuptake inhibitors, tricyclic and tetracyclic antidepressants, anticoagulants and histamine $\mathrm{H}_{1}$ and $\mathrm{H}_{2}$ receptor antagonists. Tripathi et al. [3] proposed that the mechanism of druginduced angle closure is by narrowing the angle of the anterior chamber, by pupillary dilatation, by forward movement of the iris/lens diaphragm (pupillary block glaucoma), and by swelling of the ciliary body/epithelium, lens, or vitreous body.

THC (tetrahydrocannabinol) is a cannabinoid contained in marijuana. The pupillary action of THC is controversial [4-6].

The controversy may be due to differences in the conditions under which the experiments were performed as well as to differences of drug purity.

The angle-closure glaucoma in our patient is best explained by a pushing mechanism in which the choroidal effusion leads to detachment and anterior rotation of the ciliary body and consequent angle closure.

The acute myopia can probably be explained by the forward displacement of the lens caused by supraciliary effusion, although ciliary body swelling and lens thickening could also play a role [7]. 
Hanna et al.: Unilateral Angle-Closure Glaucoma with Ciliochoroidal Effusion after the Consumption of Cannabis: A Case Report

Although the idiosyncratic drug reactions and systemic inflammatory conditions have been associated with bilateral anterior chamber shallowing and angle closure [8-11], our patient developed unilateral ciliochoroidal effusion. This can be attributed to the fact that the patient achieved medical treatment immediately after the unilateral symptoms have developed, and therefore, no symptoms in the contralateral eye developed.

There has been only 1 report of marijuana in combination with 'ecstasy' which induced acute bilateral angle closure. However, the mechanism of angle closure was not directly attributed to marijuana alone nor was there any documentation of ciliochoroidal effusion [12].

Kumar et al. [13] reported a case of 'ecstasy'-induced bilateral angle closure and transient myopia with ciliochoroidal effusion.

Marijuana affects serotonin pathways by upregulating and enhancing serotonin receptors $[14,15]$. Serotonergic innervation in the eye and the presence of serotonin and serotonin receptors in the aqueous humour and ciliary body have been reported [16, 17].

Although the precise mechanism is unknown, the supraciliary effusion in our patient could imply a serotonergic effect of marijuana.

Although it is undisputed that smoking of the marijuana plant material causes a fall in IOP in $60-65 \%$ of users, smoking reduces the IOP for only $3-4 \mathrm{~h}$, after which it returns to baseline. Continued use at a rate needed to control glaucomatous IOP would lead to a substantial systemic toxic effect revealed to as pathological changes $[18,19]$.

\section{Conclusion}

In conclusion, marijuana abuse should be kept in mind as a differential diagnosis for drug-induced acute onset of angle-closure glaucoma and transient myopia with ciliochoroidal effusion.

\section{Acknowledgements}

This research received no specific grant from any funding agency in the public, commercial or non-profit sectors.

\section{Disclosure Statement}

The authors declare no conflict of interest.

\section{References}

1 Ritch R: Argon laser treatment for medically unresponsive attacks of angle-closure glaucoma. Am J Ophthalmol 1982;94:197-204.

2 Tello C, Tran HV, Liebmann J, Ritch R: Angle closure: classification, concepts, and the role of ultrasound biomicroscopy in diagnosis and treatment. Semin Ophthalmol 2002;17:69-78.

3 Tripathi RC, Tripathi BJ, Haggerty C: Drug-induced glaucomas: mechanism and management. Drug Saf 2003;26:749-767.

4 Korczyn AD: The ocular effects of cannabinoids. Gen Pharmacol 1980;11:419-423.

5 Hepler RS, Frank IM, Ungerbider JT: Pupillary constriction after marijuana smoking. Am J Ophthalmol 1972;74:1185-1190. 
Hanna et al.: Unilateral Angle-Closure Glaucoma with Ciliochoroidal Effusion after the Consumption of Cannabis: A Case Report

-6 Korczyn AD, Eshel Y: Mydriasis induced by tetrahydrocannabinol (THC) in rats. Invest Ophthalmol Vis Sci 1982;22:408-410.

7 Craig J E, Ong T J, Louis DL, Wells JM: Mechanism of topiramate-induced acute-onset myopia and angle closure glaucoma. Am J Ophthalmol 2004;137:193-195.

8 Mandelkorn RM, Zimmerman TJ: Nonsteroidal drugs and glaucoma; in Ritch R, Shields MB, Krupin T (eds): The Glaucomas. St Louis, CV Mosby Co, 1996, pp 1189-1204.

$>9$ Wisotsky BJ, Magat-Gordon CB, Puklin JE: Angle-closure glaucoma as an initial presentation of systemic lupus erythematosus. Ophthalmology 1998;105:1170-1172.

10 Rathinam SR, Namperumalsamy P, Nozik RA, Cunningham ET Jr: Angle closure glaucoma as a presenting sign of Vogt-Koyanagi-Harada syndrome. Br J Ophthalmol 1997;81:608-609.

11 Rhee DJ, Goldberg MJ, Parrish RK: Bilateral angle-closure glaucoma and ciliary body swelling from topiramate. Arch Ophthalmol 2001;119:1723-1725.

12 Trittibach P, Freuh BE, Goldblum D: Bilateral angle-closure glaucoma after combined consumption of 'ecstasy' and marijuana. Am J Emerg Med 2005;23:813-814.

13 Kumar RS, Grigg J, Farinelli AC: Ecstasy induced acute bilateral angle closure and transient myopia. Br J Ophthalmol 2007;91:693-695.

14 Franklin JM, Mathew M, Carrasco GA: Cannabinoid-induced upregulation of serotonin 2A receptors in the hypothalamic paraventricular nucleus and anxiety-like behaviors in rats. Neurosci Lett 2013;548:165-169.

15 Franklin JM, Carrasco GA: Cannabinoid receptor agonists upregulate and enhance serotonin 2A (5-HT(2A)) receptor activity via ERK1/2 signaling. Synapse 2013;67:145-159.

16 Tobin AB, Unger W, Osborne NN: Evidence for presence of serotonergic nerves and receptors in the irisciliary body complex of the rabbit. J Neurosci 1988;8:3713-3721.

17 Briley M, Moret C: Neurobiological mechanisms involved in antidepressant therapies. Clin Neuropharmacol 1993;16:387-400.

18 Green K: Marijuana smoking vs cannabinoids for glaucoma therapy. Arch Ophthalmol 1998;116:1433-1437.

19 Jampel H: American glaucoma society position statement: marijuana and the treatment of glaucoma. J Glaucoma 2010;19:75-76.

R.H. and B.T. contributed equally to this study.

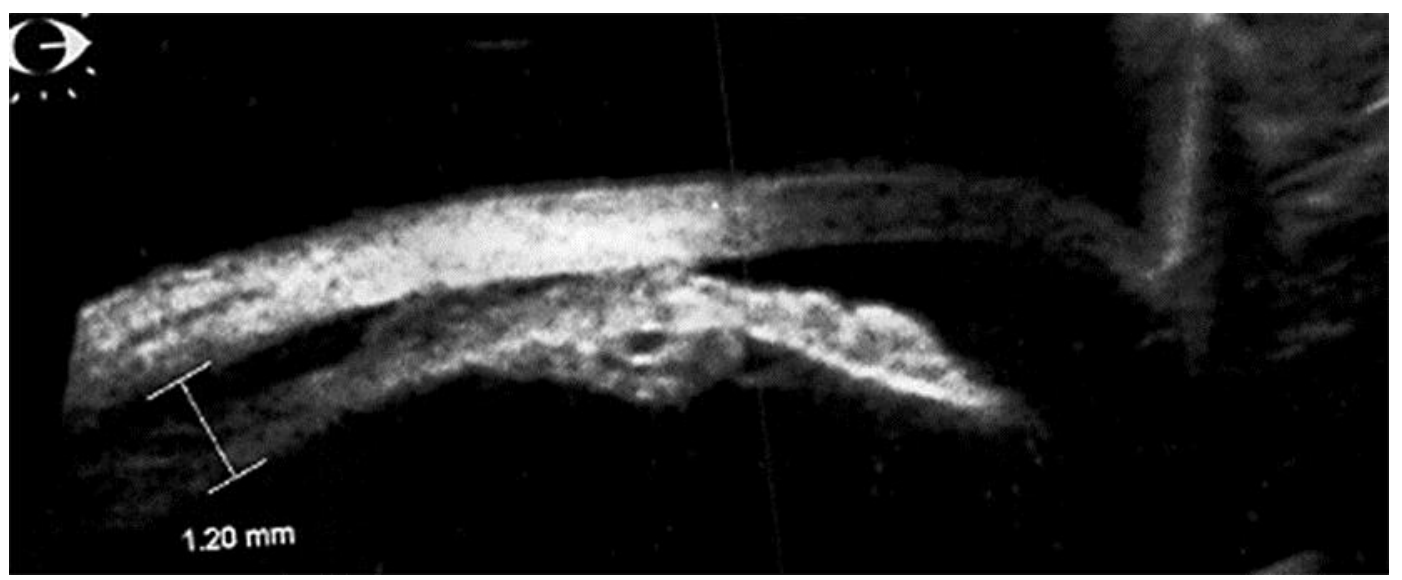

Fig. 1. A right eye UBM photograph demonstrating a closed angle, choroidal effusion, anteriorly rotated ciliary processes, and obscure ciliary sulci. 
Case Reports in

Ophthalmology
Case Rep Ophthalmol 2014;5:439-443

DOI: $10.1159 / 000370061$

(10.1159/00037006

(c) 2014 S. Karger AG, Basel

www.karger.com/cop

Hanna et al.: Unilateral Angle-Closure Glaucoma with Ciliochoroidal Effusion after the Consumption of Cannabis: A Case Report

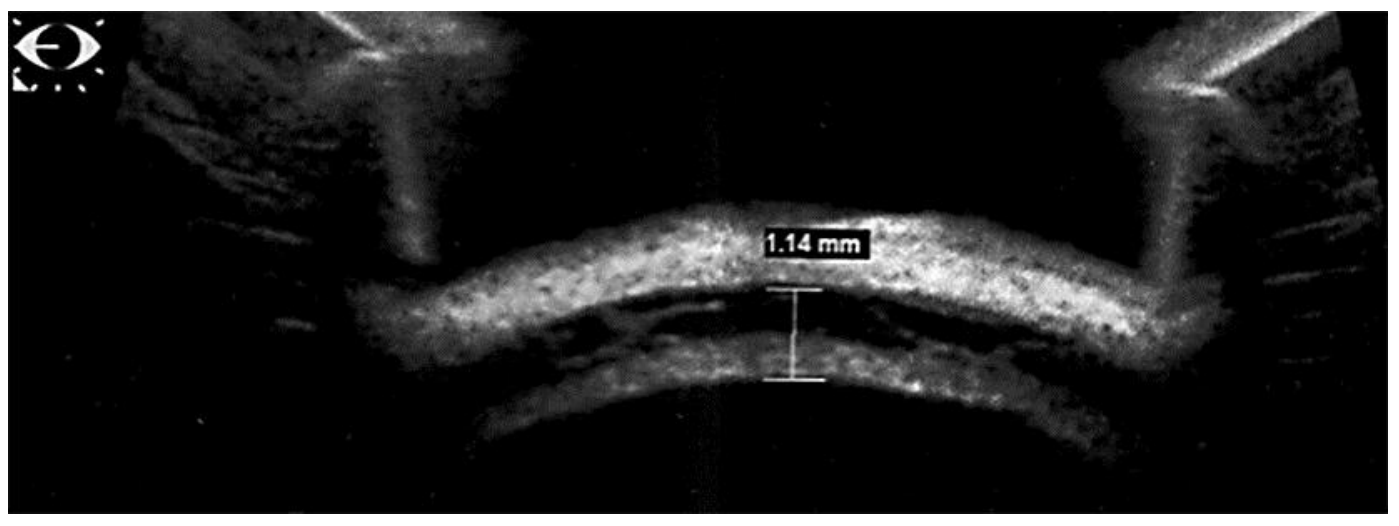

Fig. 2. A right eye UBM photograph demonstrating ciliochoroidal effusion. The choroidal thickness measured $1.14 \mathrm{~mm}$ with septate formation. 